\title{
Synthesis and Biological Evaluation of Sophoridinol Derivatives as a Novel Family of Potential Anticancer Agents
}

\author{
Chongwen $\mathrm{Bi}^{\dagger,}{ }^{\dagger}$ Caixia Zhang, ${ }^{\dagger, \S}$ Yinghong Li, $^{\dagger}$ Sheng Tang, ${ }^{\dagger}$ Shenggang Wang, ${ }^{\ddagger}$ Rongguang Shao, ${ }^{\dagger}$
} Haigen $\mathrm{Fu},{ }^{\dagger}$ Feng $\mathrm{Su},{ }^{*}+\mathrm{Z}^{+}$and Danqing Song ${ }^{* \dagger}$

${ }^{\dagger}$ Institute of Medicinal Biotechnology, Chinese Academy of Medical Science \& Peking Union Medical College, Beijing 100050, China

${ }^{\ddagger}$ College of Chemical Engineering, Qingdao University of Science and Technology, Qingdao 266042, China

\section{Supporting Information}

ABSTRACT: New $N$-substituted sophoridinic acid/ester and sophoridinol derivatives were synthesized and evaluated for their cytotoxic activity in human HepG2 hepatoma cells from the lead sophoridine (1). Among the newly synthesized compounds, sophoridinol $7 \mathbf{i}$ displayed a potential antiproliferative activity with an $\mathrm{IC}_{50}$ of $3.1 \mu \mathrm{M}$. Importantly, it exerted an almost equipotent effect against both wild MCF-7 and adriamycin (AMD)-resistant MCF-7 (MCF-7/AMD) breast carcinoma cell lines. Its mode of action was to arrest the cell cycle at the G0/G1 phase, consistent with that of the parent 1 . In addition, compound $7 \mathbf{i}$ also showed a reasonable ClogP value and favorable pharmacokinetic property with an area under the concentration-time curve (AUC) of $10.3 \mu \mathrm{M} \cdot \mathrm{h}$ in rats, indicating an ideal druggable characteristic. We consider sophoridinol derivatives to be a novel family of promising antitumor agents with an advantage of inhibiting drug-resistant cancer cells.

KEYWORDS: Sophoridine, sophoridinol, structure-activity relationship, antiproliferative, drug resistance

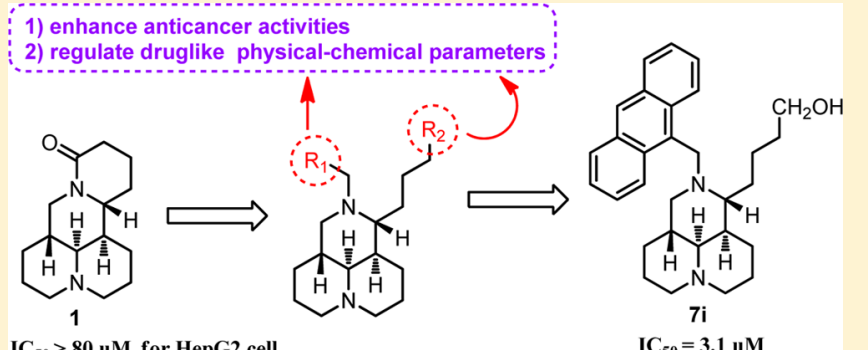

$\mathrm{IC}_{50}>80$ uM for HepG2 cell
$\mathrm{T}$ he Chinese traditional medicine Fufang Kushen injection, which was approved by Chinese FDA (CFDA) in 1995 as an anticancer drug, has been widely used to treat nonsmall cell lung carcinoma, live cancer, and gastric cancer in combination with other anticancer drugs, such as vinorelbine, cisplatin, and taxol et al. ${ }^{1-6}$ The main chemical ingredients of Fufang Kushen injection are oxymatrine, matrine, and sophoridine (1, Figure 1), ${ }^{7-9}$ and all of them are quinolizidine natural products

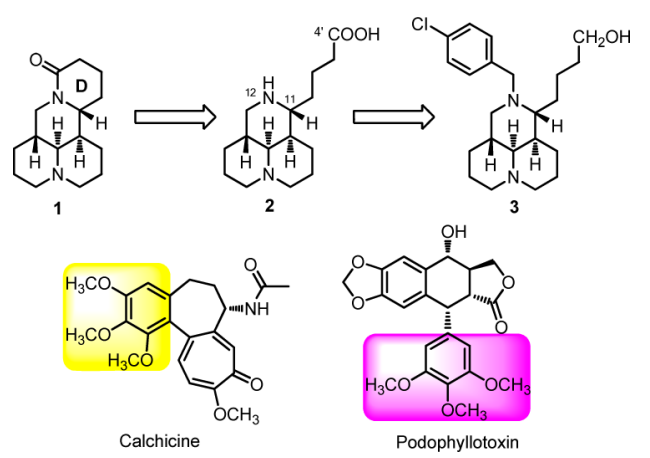

Figure 1. Chemical structures of sophoridine (1), sophoridinic acid (2), 12-N-p-chlorobenzyl sophoridinol (3), colchicine, and podophyllotoxin.

extracted from Sophora flavescens. Compound 1 alone was approved by CFDA in 2005 to cure the cancer patients with malignant trophoblastic tumors. The mechanism of action of $\mathbf{1}$ is to inhibit the DNA topoisomerase I (topo I) activity, induce cell cycle arrest at the G0/G1 phase, and cause apoptotic cell death. ${ }^{10-13}$ What's more, it has many of druggable advantages such as special chemical scaffold, flexibility structure, high solubility, and good safety profiles, suggesting that it is an ideal lead compound for further modifications and optimizations. $^{14-16}$

The structure-activity relationship (SAR) study of $\mathbf{1}$ as anticancer agent was carried out with the modifications of $D$ ring opening in our laboratory, ${ }^{17,18}$ and SAR results revealed that sophoridinic acid (2, Figure 1) analogues with a 3-ring core scaffold was more favorable than 1 with a 4-ring scaffold. The representative compound 3 (Figure 1), 12-N-p-chlorobenzyl sophoridinol, had a greatly improved antiproliferative activity in HepG2 hepatoma cells with an $\mathrm{IC}_{50}$ of $9.3 \mu \mathrm{M}$ compared to the parent $1\left(\mathrm{IC}_{50}>80 \mu \mathrm{M}\right) .{ }^{17}$ The mode of action of 3 was to inhibit DNA topo I activity and arrested the cell cycle at the G0/G1 phase, consistent with that of $1 .^{17}$ The unique chemical scaffold and promising anticancer activity of 3 provoked our strong interest to continue SAR analysis in an effort to develop a novel class of promising anticancer candidates with high druggability.

Received: July 17, 2014

Accepted: September 22, 2014

Published: September 22, 2014 
In the present study, a variety of substituents were introduced on the 12-nitrogen atom and $4^{\prime}$-carboxyl regions of compound 2, respectively, from which 27 new sophoridinic acid/ester and sophoridinol derivatives were generated and examined for their anticancer activities. Herein, we describe the synthesis, in vitro antitumor assay, SAR analysis, primary mechanism of action, and in vivo pharmacokinetic (PK) evaluation of the new compounds.

Twenty-seven target compounds were prepared using commercially available $\mathbf{1}$ as the starting material as described in Scheme 1. The sophoridinic ester $\mathbf{5}$ was obtained through a

\section{Scheme $1^{a}$}

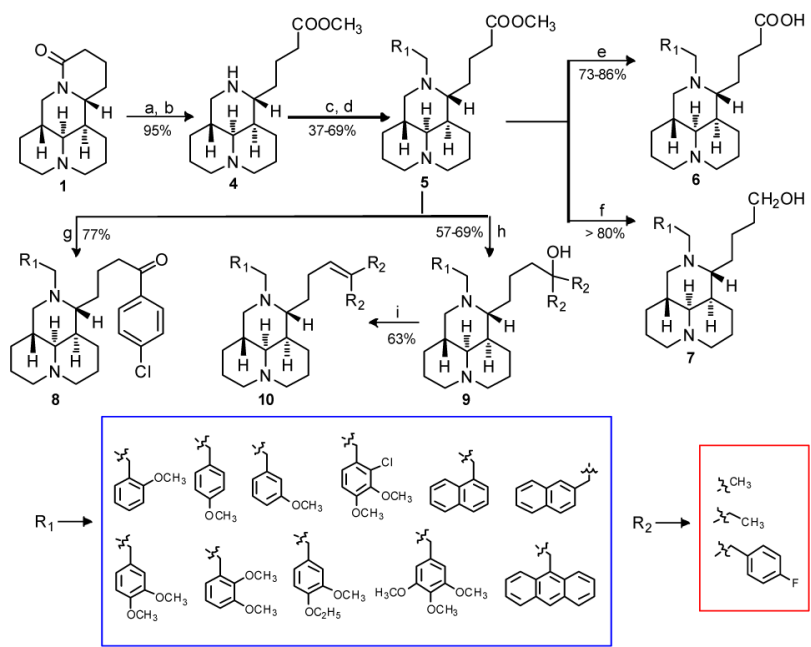

${ }^{a}$ Reagents and conditions: (a) $6 \mathrm{~N} \mathrm{HCl}, \Delta, 6 \mathrm{~h}$; (b) $\mathrm{CH}_{3} \mathrm{OH}$, r.t., $5-6 \mathrm{~h}$; (c) $\mathrm{R}_{1} \mathrm{CHO}$, triethylamine, 1,2-dichloroethane, $\Delta, 4 \mathrm{~h}$; (d) sodium triacetoxyborohydride (STB), 1,2-dichloroethane, $\Delta, 4 \mathrm{~h}$; (e) $3 \mathrm{~N}$ $\mathrm{HCl}, \Delta, 3 \mathrm{~h}$; (f) $\mathrm{LiAlH}_{4}$, THF, r.t., $4-5$ h; (g) $p$-Cl-PhMgBr, THF, r.t., $7 \mathrm{~h}$; (h) $\mathrm{R}_{2} \mathrm{MgBr}$, THF, $\Delta, 7 \mathrm{~h}$; (i) $3 \mathrm{~N}$ hydrochloride/ether, r.t., 4 h.

four-step procedure including hydrolysis, esterization, condensation, and reduction reactions as reported previously. ${ }^{17}$ The sophoridinic acid 6 was acquired by the hydrolysis of 5 in 3 $\mathrm{N} \mathrm{HCl}$ in a good yield, while the sophoridinol 7 was obtained via reduction of 5 with $\mathrm{LiAlH}_{4}$ in THF with a yield of over $80 \%$. The sophoridinic ketone $\mathbf{8}$ was synthesized via additionhydrolysis reaction of 5 with an equivalent of $p$-Cl-PhMgBr in dry THF at room temperature in a $77 \%$ yield. Similarly, the products in series 9 were also gained through the additionhydrolysis reaction of 5 with 4-5 equiv of Grignard reagents in THF at refluxing temperature with yields of $57 \%-69 \%$. The product 10 was acquired by the dehydration of 9 in a $63 \%$ yield. All crude products were purified with flash column chromatography on silica gel using $\mathrm{CH}_{2} \mathrm{Cl}_{2}$ and $\mathrm{MeOH} / \mathrm{NH}_{3} \cdot \mathrm{H}_{2} \mathrm{O}$ as gradient eluents.

All the desired compounds were evaluated for their cytotoxic activities in human HepG2 hepatoma cell lines using MTT assay with Taxol as the positive control. ${ }^{19}$ Structures of the 27 sophoridinic acid/ester and sophoridinol derivatives and their antiproliferative activities were depicted in Table 1 .

SAR analysis was first focused on the substituents at the 12nitrogen atom. Since trimethoxyphenyl group (Figure 1) is crucial for the anticancer activity in many natural medicines against cancer such as colchicine and podophyllotoxin, this group was introduced into the nitrogen atom at position 12 to create $\mathrm{N}$-trimethoxybenzyl sophoridinic ester/acid (5a and $\mathbf{6 a}$ ) and sophoridinol (7a). However, as described in Table 1, none of them was active, indicating that the trimethoxyphenyl herein was not beneficial for the anticancer activity. Next, mono/ dimethoxyphenyl groups were employed as substituents at $12-\mathrm{N}$ position to generate corresponding new derivatives $(\mathbf{5 b}-\mathbf{f}$, $\mathbf{6 b}-\mathbf{c}$, and $7 \mathbf{b}-\mathbf{f})$. The results showed that most of the sophoridinic acids/alcohols lost their cytotoxic activities partially or completely, while the sophoridinic esters $\mathbf{5 b}$ and $\mathbf{5 d}-\mathbf{f}$ afforded moderate antiproliferative activities with $\mathrm{IC}_{50}$ values ranging from 8.4 to $10.7 \mu \mathrm{M}$. It seemed that the improved anticancer activities of compounds $\mathbf{5 b}$ and $\mathbf{5} \mathbf{d}-\mathbf{f}$ were consistent with their relatively higher $C \log \mathrm{P}$ values $(>4)$ calculated by ChemBioOffice software (version 12.0).

Then, naphthalenyl and anthracenyl with high lipophilicity were added on the 12-nitrogen atom aiming at enhancing the ClogP values, thereby enhancing the activity against tumor, with which many new corresponding compounds $(5 \mathrm{~g}-\mathbf{i}, \mathbf{6 d}-\mathbf{e}$, and $7 \mathrm{~g}-\mathbf{i}$ ) were made and examined. As anticipated, the sophoridinic esters $(\mathbf{5 g}-\mathbf{i})$ and sophoridinols $(\mathbf{7} \mathbf{g}-\mathbf{i})$ displayed higher potency with $\mathrm{IC}_{50}$ values ranging from 3.1 to $7.9 \mu \mathrm{M}$, much better than that of Taxol $\left(\mathrm{IC}_{50}=15.6 \mu \mathrm{M}\right)$. Especially, compound $7 \mathbf{i}$ with a 9-anthracene at the $12-\mathrm{N}$ position exhibited a potent activity against HepG 2 cancer with an $\mathrm{IC}_{50}$ of $3.1 \mu \mathrm{M}$. Subsequently, the 9-anthracenyl on the 12-nitrogen atom was retained, and a couple of sophoridinic ketone (8), sophoridinols $(9 \mathbf{a}-\mathbf{b})$, and sophoridinic alkene (10) were constructed and measured. The results showed that all of them had favorable antiproliferative activities with $\mathrm{IC}_{50}$ between 2.0 and $5.3 \mu \mathrm{M}$ owing to the improvement of ClogP values ranging from 6.8 and 9.5. Among the active compounds, sophoridinic esters $5 \mathbf{g}-\mathbf{i}$ had metabolic instabilities in vivo owing to the metabolically labile ester group. Therefore, sophoridinols $\mathbf{7 g}$ and $7 \mathbf{i}$ bearing potent anticancer effects as well as reasonable ClogP values were selected out as the representative compounds for further investigation.

Evaluation of compounds $7 \mathrm{~g}$ and $7 \mathbf{i}$ against drug-resistant cancer cell lines were carried out. In this experiment, we tested their activity against human wild MCF-7 and adriamycin (AMD)-resistant MCF-7 (MCF-7/AMD) breast carcinoma cell lines, ${ }^{20}$ with $\mathrm{AMD}$ as a reference control. As described in Table 2, AMD exhibited a promising activity against wild MCF-7 with an $\mathrm{IC}_{50}$ of $0.88 \mu \mathrm{M}$, compared with that of $94 \mu \mathrm{M}$ in the MCF$7 / \mathrm{AMD}$ cells. Notably, compounds $7 \mathbf{g}$ and $7 \mathbf{i}$ afforded an almost equipotent antiproliferative effect against both MCF-7 $\left(\mathrm{IC}_{50}\right.$ of 9.0 and $\left.5.6 \mu \mathrm{M}\right)$ and drug-resistance MCF-7/AMD cells $\left(\mathrm{IC}_{50}\right.$ of 9.5 and $5.9 \mu \mathrm{M}$ ), suggesting a different anticancer mechanism of action from AMD.

To verify the possible change of mechanism of action after the structure modifications, flow cytometric analysis in the HepG2 cells was carried out to learn whether or not compound $7 \mathbf{i}$ is able to cause G0/G1 arrest. The HepG2 cells were treated for $24 \mathrm{~h}$ without or with $7 \mathbf{i}$ at the different concentrations of $1.25,2.5$, and $5.0 \mu \mathrm{g} / \mathrm{mL}$, respectively. As shown in Figure 2, compound $7 \mathbf{i}$ arrested the HepG2 cells at the G0/G1 phase as anticipated, indicating a similar mechanism of action with its parent compound $\mathbf{1}$.

Single dose PK investigation for compound $7 \mathbf{i}$ was performed in adult male Sprague-Dawley (SD) rats. Compound $7 \mathbf{i}$ was administered via oral routes $(25 \mathrm{mg} / \mathrm{kg})$, and nine blood samples $(0.3 \mathrm{~mL})$ were collected over a $24 \mathrm{~h}$ period. As described in Figure 3 and Table 3, the compound $7 \mathbf{i}$ was rapidly absorbed with a $T_{\max }$ of $4.6 \mathrm{~h}$, a favorable half-life of $12 \mathrm{~h}$, and a mean residence time (MRT) of $5.4 \mathrm{~h}$. The area under the concentration-time curve (AUC) of $7 \mathbf{i}$ was $10.3 \mu \mathrm{M} \cdot \mathrm{h}$, which 
Table 1. Structure-Activity Relationships of the Newly Synthesized Compounds for Their Antiproliferative Activities in HepG2 Cells

\begin{tabular}{|c|c|c|c|c|c|c|c|c|c|}
\hline Compd & $\mathrm{R}_{1}$ & $\mathrm{R}_{2}$ & $\mathrm{IC}_{50}(\mu \mathrm{M})$ & $\mathrm{Clog} \mathrm{P}^{\mathrm{a}}$ & Compd & $\mathrm{R}_{1}$ & $\mathrm{R}_{2}$ & $\mathrm{IC}_{50}(\mu \mathrm{M})$ & $C \log \mathrm{P}^{\mathrm{a}}$ \\
\hline $5 a$ & $\mathrm{H}$ & $\mathrm{COOCH}_{3}$ & $>40$ & 3.52 & $7 \mathbf{b}$ & & $\mathrm{CH}_{2} \mathrm{OH}$ & $15.7 \pm 7.6$ & 4.01 \\
\hline $5 \mathbf{b}$ & 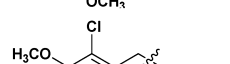 & $\mathrm{COOCH}_{3}$ & $8.4 \pm 4.1$ & 4.44 & $7 \mathrm{c}$ & & $\mathrm{CH}_{2} \mathrm{OH}$ & $>40$ & 3.98 \\
\hline $5 c$ & & $\mathrm{COOCH}_{3}$ & $>40$ & 3.88 & $7 \mathrm{~d}$ & & $\mathrm{CH}_{2} \mathrm{OH}$ & $23.6 \pm 2.5$ & 4.34 \\
\hline $5 d$ & $\mathrm{CH}_{2} \mathrm{C}_{6} \mathrm{H}_{4} \mathrm{OCH}_{3-\mathrm{o}}$ & $\mathrm{COOCH}_{3}$ & $10.3 \pm 0.4$ & 4.14 & $7 e$ & $\mathrm{CH}_{2} \mathrm{C}_{6} \mathrm{H}_{4} \mathrm{OCH}_{3}-\mathrm{O}$ & $\mathrm{CH}_{2} \mathrm{OH}$ & $34.6 \pm 4.0$ & 3.72 \\
\hline $5 e$ & $\mathrm{CH}_{2} \mathrm{C}_{6} \mathrm{H}_{4} \mathrm{OCH}_{3}-m$ & $\mathrm{COOCH}_{3}$ & $10.7 \pm 0.3$ & 4.14 & $7 f$ & $\mathrm{CH}_{2} \mathrm{C}_{6} \mathrm{H}_{4} \mathrm{OCH}_{3-p}$ & $\mathrm{CH}_{2} \mathrm{OH}$ & $>40$ & 3.72 \\
\hline $5 f$ & $\mathrm{CH}_{2} \mathrm{C}_{6} \mathrm{H}_{4} \mathrm{OCH}_{3-p}$ & $\mathrm{COOCH}_{3}$ & $10.7 \pm 0.4$ & 4.14 & $7 \mathrm{~g}$ & 1-methylnaphthalene & $\mathrm{CH}_{2} \mathrm{OH}$ & $6.8 \pm 1.7$ & 4.97 \\
\hline $5 g$ & 1-methylnaphthalene & $\mathrm{COOCH}_{3}$ & $3.3 \pm 1.0$ & 5.39 & $7 \mathrm{~h}$ & 2-methylnaphthalene & $\mathrm{CH}_{2} \mathrm{OH}$ & $7.9 \pm 2.7$ & 4.97 \\
\hline $5 \mathrm{~h}$ & 2-methylnaphthalene & $\mathrm{COOCH}_{3}$ & $5.8 \pm 0.8$ & 5.39 & $7 \mathbf{i}$ & 9-methylanthracene & $\mathrm{CH}_{2} \mathrm{OH}$ & $3.1 \pm 0.6$ & 6.15 \\
\hline $5 i$ & 9-methylanthracene & $\mathrm{COOCH}_{3}$ & $4.3 \pm 0.6$ & 6.57 & 8 & 9-methylanthracene & & $2.0 \pm 0.4$ & 8.75 \\
\hline $6 \mathbf{a}$ & & $\mathrm{COOH}$ & $>40$ & 0.87 & $9 a$ & 9-methylanthracene & & $2.1 \pm 0.2$ & 6.86 \\
\hline $6 b$ & & $\mathrm{COOH}$ & $>40$ & 1.23 & $9 b$ & 9-methylanthracene & & $2.7 \pm 0.8$ & 7.92 \\
\hline $6 c$ & $\mathrm{CH}_{2} \mathrm{C}_{6} \mathrm{H}_{4} \mathrm{OCH}_{3}-\mathrm{O}$ & $\mathrm{COOH}$ & $>40$ & 1.49 & 10 & 9-methylanthracene & & $5.3 \pm 0.2$ & 9.52 \\
\hline $6 d$ & 1-methylnaphthalene & $\mathrm{COOH}$ & $>40$ & 2.75 & 1 & & & $>80$ & \\
\hline $6 e$ & 2-methylnaphthalene & $\mathrm{COOH}$ & $>40$ & 2.75 & 3 & & & $9.3 \pm 2.1$ & \\
\hline $7 a$ & & $\mathrm{CH}_{2} \mathrm{OH}$ & $>40$ & 3.10 & Taxol & & & $15.6 \pm 2.3$ & \\
\hline
\end{tabular}

${ }^{a} \mathrm{ClogP}$ value was generated by ChemBioOffice software (version 12.0).

Table 2. $\mathrm{IC}_{50}(\mu \mathrm{M})$ Values of $7 \mathrm{~g}$ and $7 \mathrm{i}$ in MCF-7 and MCF-7/ AMD Breast Carcinoma Cell Lines

$\begin{array}{lcc} & \text { MCF-7 } & \text { MCF-7/AMD } \\ 7 \mathrm{~g} & 9.07 \pm 1.22 & 9.51 \pm 1.85 \\ 7 \mathrm{i} & 5.63 \pm 0.33 & 5.94 \pm 1.07 \\ \text { AMD } & 0.88 \pm 0.15 & 94.1 \pm 7.79\end{array}$

is greater than the $\mathrm{IC}_{50}$ value $(3.1 \mu \mathrm{M})$ of antiproliferative activity in vitro. The $\mathrm{PK}$ profiles of $7 \mathbf{i}$ were not as good as those of compound $3,{ }^{17}$ and this might be due to the higher ClogP value $(\mathrm{C} \log \mathrm{P}=6.15)$ of this compound.

Taken together, 27 new sophoridinic acid/ester and sophoridinol derivatives were constructed and evaluated for their antitumor activities in vitro. SAR analysis revealed that (i) 
Table 3. Pharmacokinetic Profile ${ }^{a}$ of $7 \mathbf{i}$ in Rats after a Single Oral Administration $(n=3)$

$\begin{array}{cccccc}\text { dosage }(\mathrm{mg} / \mathrm{kg}) & T_{\max }(\mathrm{h}) & C_{\max }(\mu \mathrm{M}) & \mathrm{AUC}_{0-t}(\mu \mathrm{M} \cdot \mathrm{h}) & \mathrm{AUC}_{0-\infty}(\mu \mathrm{M} \cdot \mathrm{h}) & \mathrm{MRT}(\mathrm{h}) \\ 25 & 4.6 \pm 1.2 & 3.4 \pm 0.5 & 10.3 \pm 1.4 & 10.5 \pm 1.2 & 5.4 \pm 0.1\end{array}$

${ }^{a} \mathrm{PK}$ parameters were calculated by noncompartmental analysis using WinNonlin, version 5.3.

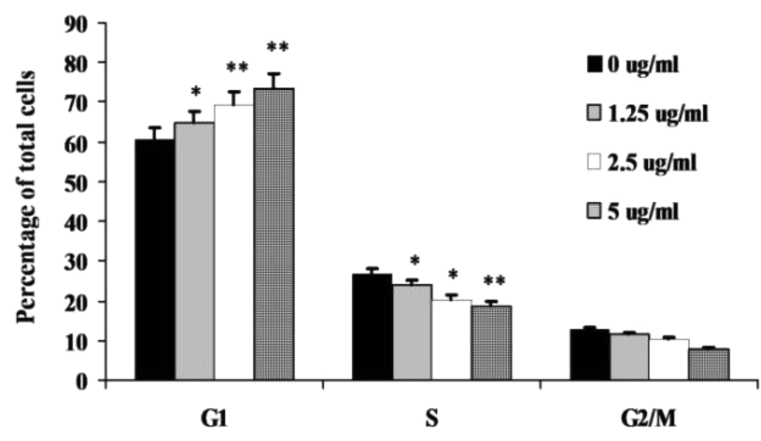

Figure 2. Cell cycle analysis of 7i. HepG2 cells were incubated without (control) or with compounds at different concentrations (1.25, 2.5, and $5.0 \mu \mathrm{g} / \mathrm{mL}$ ) for $24 \mathrm{~h}$. Cells were then analyzed for their cell cycle distribution using flow cytometry. (*) $P<0.05$; (**) $P<0.01$ as compared to that of control group.

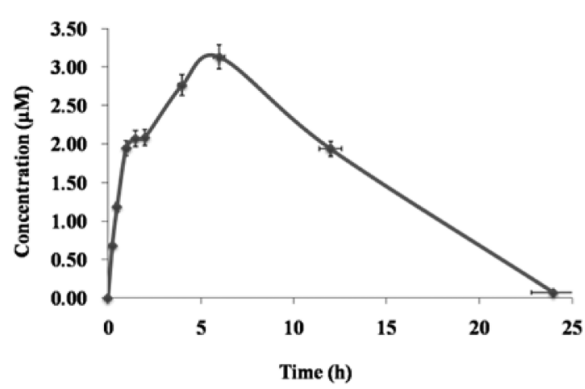

Figure 3. Mean plasma concenreation-time curve of compound $7 \mathbf{i}$ after single oral administration of $25 \mathrm{mg} / \mathrm{kg}$ in SD rats $(n=3)$. Pharmacokinetic parameters were calculated by noncompartmental analysis using WinNonlin, version 5.3.

two suitable substituents on the 12-nitrogen atom and carboxyl region were helpful for keeping good antitumor activity. (ii) The two moieties could be introduced decorating various substituents in order to regulate the druglike physical-chemical properties of the compounds. The SAR results provide useful information on further strategic optimization. Among them, sophoridinol $7 \mathbf{i}$ showed an equipotent effect against wild MCF-7 and MCF-7/ AMD breast carcinoma cell lines. Its mechanism of action was to arrest the cell cycle at the G0/G1 phase consistent with that of $\mathbf{1}$. In addition, it also showed a good PK profile in vivo, indicating a good druggable characteristic. Thus, we consider sophoridinol analogues to be a new family of promising antitumor agents with an advantage of inhibiting drug-resistant cancer cells.

\section{ASSOCIATED CONTENT}

\section{S Supporting Information}

Synthetic procedure, analytical data, cytotoxicity assay, cell cycle analysis, and PK evaluation. This material is available free of charge via the Internet at http://pubs.acs.org.

\section{AUTHOR INFORMATION}

\section{Corresponding Authors}

*(F.S.) Tel: +86 532 84023947. Fax: +86 53284022924 .

E-mail: qdkdsufeng@hotmail.com.
*(D.S.) Tel: +86 10 63165268. Fax: +86 10 63165268. E-mail: songdanqingsdq@hotmail.com.

\section{Author Contributions}

$\S$ (C.B. and C.Z.) These authors contributed equally to this work.

\section{Funding}

This work was supported by the National Mega-Project for Innovation Drugs (2012ZX09301002-001-017) and Student Fund of Innovation Project of Peking Union Medical College.

Notes

The authors declare no competing financial interest.

\section{ABBREVIATIONS}

SAR, structure-activity relationship; MTT, tetrazolium bromide; AMD, adriamycin; THF, tetrahydrofuran; TLC, thin layer chromatography

\section{REFERENCES}

(1) Sun, M.; Cao, H.; Sun, L.; Dong, S.; Bian, Y.; Han, J.; Zhang, L.; Ren, S.; Hu, Y.; Liu, C.; Xu, L.; Liu, P. Antitumor activities of kushen: literature review. J. Evidence-Based Complementary Altern. Med. 2012, 2012, 373219.

(2) Wei, R.; Yang, D. Y.; Jiang, W. Z.; Dai, Y. Y.; Wan, L. Y.; Yang, Z. Efficacy of Yanshu injection (a compound Chinese traditional medicine) combined with concurrent radiochemotherapy in patients with stage III nasopharyngeal carcinoma. Zhonghua Zhongliu Zazhi 2011, 33, 391-394.

(3) Wang, C. Y.; Bai, X. Y.; Wang, C. H. Traditional Chinese medicine: a treasured natural resource of anticancer drug research and development. Am. J. Chin. Med. 2014, 42, 543-559.

(4) Liu, J.; Liu, Y. Influence of erbanxiao solution on inhibiting angiogenesis in stasis toxin stagnation of non-small cell lung cancer. $J$. Tradit. Chin. Med. 2013, 33, 303-306.

(5) Guan, C. N.; Cai, L. Z.; Yue, L. Q.; Zhang, Y. Clinicel study on treatment of advanced primary liver cancer by Yanshu injection combining with chemotherapy. Zhongguo Zhongyao Zazhi 2006, 31, $510-512$.

(6) Sun, Q.; Ma, W.; Gao, Y.; Zheng, W.; Zhang, B.; Peng, Y. Metaanalysis: therapeutic effect of transcatheter arterial chemoembolization combined with compound kushen injection in hepatocellular carcinoma. Afr. J. Tradit. Complementary Altern. Med. 2012, 9, 178188

(7) Liu, J.; Xue, M.; Huang, X.; Wang, S.; Jiang, Z.; Zhang, L. Pharmacokinetic of four alkaloids of Yanshu injection in Beagel dogs. Zhongguo Zhongyao Zazhi 2012, 37, 1845-1849.

(8) Qi, L.; Zhang, J.; Zhang, Z. Determination of four alkaloids in compound Kushen Injection by high performance liquid chromatography with ionic liquid as mobile phase additive. Sepu 2013, 31, 249253.

(9) Tian, J.; Wang, W. H.; Gao, H. M.; Wang, Z. M. Determination of matrine, sophoridine and oxymatrine in Compound Kushen Injection by HPLC. Zhongguo Zhongyao Zazhi 2007, 32, 222-224.

(10) Zheng, K.; Li, C.; Shan, X.; Liu, H.; Fan, W.; Wang, Z. A study on isolation of chemical constituents from Sophora flavescens Ait. and their anti-glioma effects. Afr. J. Tradit. Complementary Altern. Med. 2014, 11, 156-160.

(11) Deng, H.; Luo, H.; Huang, F.; Li, X.; Gao, Q. Inhibition of proliferation and influence of proto-oncogenes expression by matrine in C6 cell. Zhongyaocai 2004, 27, 416-419. 
(12) Guo, L.; Xue, T. Y.; Xu, W.; Gao, J. Z. Matrine promotes G0/ G1 arrest and down-regulates cyclin D1 expression in human rhabdomyosarcoma cells. Panminerva Med. 2013, 55, 291-296.

(13) Li, X. M.; Wu, Y. G.; Pan, D. X.; Wu, L. K.; Yu, Y. H. Sophoridine is a new antitumor medicine with new molecular structure. Zhongguo Xinyao Zazhi 2006, 15, 654-657.

(14) Ye, G.; Zhu, H. Y.; Li, Z. X.; Ma, C. H.; Fan, M. S.; Sun, Z. L.; Huang, C. G. LC-MS characterization of efficacy substances in serum of experimental animals treated with Sophora flavescens extracts. Biomed. Chromatogr. 2007, 21, 655-660.

(15) Li, Y. M.; Min, G.; Xue, Q.; Chen, L.; Liu, W.; Chen, H. Highperformance liquid chromatographic method for simultaneous determination of sophoridine and matrine in rat plasma. Biomed. Chromatogr. 2004, 18, 619-624.

(16) Hu, P. Y.; Zheng, Q.; Chen, H.; Wu, Z. F.; Yue, P. F.; Yang, M. Pharmacokinetics and distribution of sophoridine nanoliposomes in rats. Zhongguo Xinyao Zazhi 2012, 21, 2662-2666.

(17) Bi, C. W.; Zhang, C. X.; Li, Y. H.; Tang, S.; Deng, H. B.; Zhao, W. L.; Wang, Z.; Shao, R. G.; Song, D. Q. Novel N-substituted sophoridinol derivatives as anticancer agents. Eur. J. Med. Chem. 2014, $81,95-105$

(18) Li, X.; Zhao, W. L.; Jiang, J. D.; Ren, K. H.; Du, N. N.; Li, Y. B.; Wang, Y. X.; Bi, C. W.; Shao, R. G.; Song, D. Q. Synthesis, structureactivity relationship and biological evaluation of anticancer activity for novel N-substituted sophoridinic acid derivatives. Bioorg. Med. Chem. Lett. 2011, 21, 5251-5254.

(19) Hu, G. Q.; Yang, Y.; Yi, L.; Wang, G. Q.; Duan, N. N.; Wen, X. Y.; Cao, T. Y.; Xie, S. Q.; Huang, W. L. Design, synthesis and antitumor activity of $\mathrm{C} 3 / \mathrm{C} 3$ bis-fluoroquonolones cross-linked with [1,2,4]triazolo[3,4-b] [1,3,4]thiadiazole. Acta Pharm. Sin. B 2011, 1, $172-177$.

(20) Emirdağ-Öztürk, S.; Karayıldırım, T.; Capc1-Karagöz, A.; Alankuş-Çalışkan, O.; Ozmen, A.; Poyrazoğlu-Çoban, E. Synthesis, antimicrobial and cytotoxic activities, and structure-activity relationships of gypsogenin derivatives against human cancer cells. Eur. J. Med. Chem. 2014, 82, 510-512. 